\title{
EDUCAÇÃO POPULAR EM SAÚdE NA COMUNIDADE: AÇÕES EDUCATIVAS PARA PACIENTES COM PÉ DIABÉTICO EM DUAS UNIDADES BÁSICAS DE SAÚDE EM RECIFE - PERNAMBUCO
}

\author{
Cybelle Gomes de Souza ${ }^{1}$ \\ Cristiane Rodrigues de Carvalho ${ }^{2}$ \\ Cristiano do Nascimento Siqueira ${ }^{3}$
}

\begin{abstract}
A educação em saúde, importante meio de promoção de saúde e prevenção de doenças e agravos, tem sido utilizada de maneira hierárquica e vertical, então educação popular criada por Paulo Freire vem como opção, trazendo o empoderamento do povo por parte da educação e da aprendizagem, através do ensino horizontal e da participação popular, principalmente no âmbito da saúde. No caso da Diabetes Mellitus não difere, é possível observar a necessidade do aprendizado, por parte da população em situação de vulnerabilidade, acerca da doença e seus agravos. Um dos agravos principais e principal motivo de amputações do mundo é o Pé Diabético. A necessidade do aprendizado da população acerca dos métodos de autocuidado é inerente à situação saúde-doença e a educação popular em saúde, através das suas metodologias é imprescindível por dar autonomia ao paciente, promovendo, desta forma, seu autocuidado e em consequência saúde.
\end{abstract}

Palavras- chave: Educação popular. Educação em saúde. Diabetes mellitus. Pé diabético. Promoção à saúde.

\section{INTRODUÇÃO}

A educação em Saúde é um meio de destaque na promoção à saúde, e um veio muito importante é o da Educação Popular (EP). O Ministério da Saúde (MS) do Brasil interveio a partir da criação da Política Nacional de Educação Popular e Saúde e dos Cadernos de Educação Popular e Saúde, I e II, a fim de reconhecer a importância das ações educativas como estratégias para enfrentamento das questões de saúde pública e de promoção da saúde (DANTAS et al, 2020).

Segundo Dantas et al (2020), a Educação Popular foi concretizada com a Prática de alfabetização de Paulo Freire no Brasil, que não só ensinava no âmbito científico, mas preparava os educandos para as responsabilidades social e política. $O$ trabalho realizado articulou-se com os movimentos da Reforma Sanitária, da Saúde Coletiva e do Sistema Único de Saúde. É imprescindível a um processo de educação popular, principalmente na saúde e mais especificamente no tratamento da diabetes, a inclusão dos saberes do(a) educando(a) e que haja seu protagonismo (DANTAS et al, 2020). 
As Diretrizes da Sociedade Brasileira de Diabetes (SBD) (2019, P. 19) conceitua o de diabetes mellitus (DM), que: "Consiste em um distúrbio metabólico caracterizado por hiperglicemia persistente, decorrente de deficiência na produção de insulina ou na sua ação, ou em ambos os mecanismos". Foi estimado em 2017, que $8,8 \%$ da população mundial vivia com diabetes. A doença pode evoluir com complicações agudas como a hipoglicemia, e crônicas que podem ser divididas em microvasculares e macrovasculares o que auxiliam na formação de um agravo da doença, o Pé Diabético.

Um conceito de pé diabético é: "infecção, ulceração e/ou destruição de tecidos moles associadas a alterações neurológicas e vários graus de doença arterial periférica (DAP) nos membros inferiores" (SBD, 2019, P. 341). De acordo com a SBD (2019), 85\% dos casos de Pé Diabético resultantes de Úlceras de Pé Diabéticos, causa mais comum nos países em desenvolvimento, resultam em amputação. O que demonstra a importância de ações de promoção à saúde e prevenção desse agravo.

Os portadores da doença precisam compreender sua enfermidade, reconhecer os sinais de alerta das complicações e saber como responder a isso. E cabe ao profissional de saúde certificar-se que os portadores de diabetes tenham conhecimento sobre suas condições e estejam capacitadas para o enfrentamento a sua patologia. Os resultados alcançados são menos sintomas, menos complicações, menos incapacidades, e uma das formas de atingir esse objetivo é realizando ações de educação popular dentro com os portadores da doença (BRASIL, 2014).

Paulo Freire demonstra a necessidade de pessoas engajadas em ser "sujeitos que refazem o mundo" afirmando que "a conscientização é um compromisso histórico" (FREIRE, 1980). E é com essa perspectiva que a Educação Popular em Saúde vem sendo construída no SUS, e é observando as vulnerabilidades da população que se torna possível direcionar as ações de educação popular. Desta forma esse artigo tem o intuito de trazer à discussão, a utilização das ações referenciadas na EP e os indivíduos que são alcançados por elas. 


\section{DESENVOLVIMENTO}

\section{Educação como Ferramenta para Promoção de Saúde}

Conforme a Política Nacional de Promoção à Saúde (2014), a educação em saúde tem importante destaque na qualificação e fortalecimentos da promoção à saúde. O conjunto de práticas pedagógicas de caráter participativo e emancipatório, que perpassa vários campos de atuação e tem como objetivo sensibilizar, conscientizar e mobilizar para o enfrentamento de situações individuais e coletivas que interferem na qualidade de vida é chamado Educação em Saúde (BRASIL, 2009).

A educação em saúde apresenta atividades preventivas, com foco nas doenças, como evitá-las, suas consequências e seu restabelecimento, e seu tratamento utilizando-se A diferença entre as práticas de educação em saúde tradicional e contemporâneas são as formas de abordagem. As ações tradicionais tratam do princípio biomédico, da doença e como evitá-las, sendo feito de maneira vertical e hierárquica, já as contemporâneas são dialógicas, abordam temas que estão relacionados com o cotidiano das pessoas, como lazer, alimentação saudável, conhecimento popular, com as intervenções sendo feitas de forma individual ou em grupo (LIMA et al, 2019).

As primeiras ações de educação em saúde no país, Iniciadas no do século $\mathrm{XIX}$, eram voltadas aos segmentos sociais de maior renda.No caso das classes mais baixas, o interesse em mudar o padrão sanitário dos escravos e serviçais acontecia apenas quando estes eram considerados foco de doença (GONÇALVES; DAL-FARRA, 2018).

Ayres admite que a Educação em Saúde no Brasil é dominada por perspectivas unidirecionais, centradas na transmissão de informação; e procede, portanto, sua exclamação de que "mesmo no Brasil, a pátria de Paulo Freire, esse importante filósofo e metodólogo da educação, modelos limitados e limitantes de educação preventiva foram amplamente importados e utilizados" (p. 16) (SEVALHO, 2018, p. 181). 
No caso das pessoas portadoras de doenças crônicas são utilizados dispositivos metodológicos para promoção de mudanças de atitudes e estilo de vida, com o uso de tecnologias contemporâneas, implementados com a expectativa de melhoria da assistência. Cada usuário necessita de uma abordagem de acordo com suas necessidades o que implica na adesão do paciente ao plano de cuidados o que traz controle metabólico e qualidade de vida aos portadores de doenças como a Diabetes (LIMA et al, 2019).

É necessário observar que a crença de que todos os profissionais sempre estão realizando ações educativas pode demonstrar a ideia de que para $r$ Educação em Saúde ser realizada não é necessário estudo acerca do tema ou método, que basta apenas improvisar. A educação em saúde pode se tornar um poderoso instrumento de domesticação e gerar vulnerabilidade social, por isso é importante analisar a intenção das ações que serão realizadas. A ideia de vulnerabilidade, na Educação Popular em Saúde, na perspectiva social, compõe a percepção crítica de contextos onde a população enfrenta situações de opressão e luta cotidianamente pela conquista de liberdade e autonomia. É desta forma que é estabelecida a relação com a pedagogia crítica de Paulo Freire (SEVALHO, 2018).

\section{Educação Popular em Saúde e Paulo Freire}

Política Nacional de Educação Popular em Saúde, instituída pela Portaria 2.761/2013, em seu Art. 3o apresenta os seguintes princípios orientadores: I diálogo; II - amorosidade; III - problematização; IV - construção compartilhada do conhecimento; V - emancipação; e VI - compromisso com a construção do projeto democrático e popular (BRASIL, 2013).

O marco legal que permite a institucionalização da Educação Popular em Saúde é a Constituição de 1988, que apresenta a saúde como um direito de todos e dever do Estado, garantida pelo Sistema Único de Saúde (SUS). O SUS que possui como um de seus princípios fundamentais, o princípio da participação popular, que garante à população a participação do povo nas decisões de políticas públicas de saúde (AIMONDI et al, 2018). 
Segundo MACIAZEKI-GOMES et al, (2016), a Política Nacional de Educação Popular, baseada a princípios éticos que potencializam as relações humanas realizadas no ato de educar, e é norteado para a determinação de processos educativos e de trabalho social de cunho emancipatório. é disposta a favor da "promoção da autonomia das pessoas, à horizontalidade entre os saberes populares e técnico-científicos, à formação da consciência crítica, à cidadania participativa, ao respeito às diversas formas de vida", com a intenção de enfrentar as "desigualdades sociais e todas as formas de discriminação, violência e opressão".

A Educação Popular cumpre o papel de promover autonomia e empoderamento das pessoas, através da prática de práxis humana, que utiliza a ação e reflexão sobre a realidade vivida, tornando-as capazes de entender e atuar sobre o mundo. Ao juntar essa a problematização realizada, ao usar a ação e reflexão com espaços de debate democrático, ocorre que o aprendizado horizontal, sem um detentor de saber e onde todos aprendem (AIMONDI et al, 2018).

Conforme o artigo de Sevalho (2018), mesmo com o desconhecimento e desqualificação, por parte dos que defendem a subordinação do povo frente às elites Paulo Freire recebe, em 2012, o título de Patrono da Educação no Brasil. E em 1989 traz a liberdade como, a matriz que atribui sentido a uma prática educativa eficaz, o que dá fundamentação para a Educação Libertadora, que dialoga com a população através da problematização e reflexão crítica com a participação livre e reflexão crítica do educados(as). É chamada reflexão crítica quando pessoas conscientes e socialmente responsáveis são formadas utilizando a práxis humana, porém a educação popular transcende um conjunto de "normas" e "princípios, realizando assim a educação livre (GONÇALVES; DAL-FARRA, 2018).

Segundo Freire a problematização é consequência do diálogo, e dar-se ao ocorrer um estudo do "universo temático do povo" ou do "conjunto de seus temas geradores", resgatando saberes locais/regionais, valorizando o patrimônio cultural dos educandos e, ao mesmo tempo, levando a estes o saber acadêmico. Para ele, A partir do diálogo torna-se possível é o instrumento que possibilita manter um contexto observando os diversos pontos de vista apresentados pelos envolvidos, o que é a fundamental na comunicação entre pessoas onde a 
relação é horizontal, não hierárquica e de solidariedade, demonstrando comprometimento mútuo, no intuito de realizar a transformação do meio em que vivem e de sua situação de vulnerabilidade (GONÇALVES; DAL-FARRA, 2018).

Por mais que Freire tenha criado e utilize suas referências teóricas políticas e éticas, altamente coerentes, ele não permanece recluso a essas concepções. Esses conceitos são mais utilizados como alicerce, ponto de referência, em favor do desempenho dos diversos contextos em que são lidos. A preocupação em dizer o que são, é quase nula, mas o que podem vir a ser é grande enfoque, o que é realizado por meio da ação (PARO, 2020).

Em relação ao combate por parte de Freire a centralidade na transmissão de informações, Paro (2020) refere que, entende-se que as aproximações ao legado pedagógico de Paulo Freire pela saúde, sendo feitas de maneira divergente, deve-se a histórica escala vertical hierárquica de transmissão de conhecimento. Retirando dessa forma a participação do povo na mudança de comportamentos, o que gera tensionamentos da transmissão de informações e a dialogia freireana.(PARO, 2020).

Em 2013, a Política Nacional de Educação Popular em Saúde, através de seus cadernos, cumpre o papel de reassumir o compromisso com os princípios do SUS de universalidade, integralidade, equidade e, principalmente, com a participação social. A Política utiliza a estratégia política-pedagógica da Educação Popular em Saúde, definindo que a promoção, proteção e recuperação da saúde deve ser realizada por meio de diálogos. Portanto, proporciona desta forma, a troca dos diversos saberes, levando à construção de conhecimentos individuais e coletivos, com empoderamento dos indivíduos e respectivos grupos, levando-os a fomentar a participação social na consolidação e construção do SUS (AMONDI et al, 2018).

\section{Diabetes, pé diabético e autocuidado}

O termo "diabetes mellitus" (DM) remete-se a uma doença crônica associada à desordem do metabolismo de etiologias diversas, representado por hiperglicemia e transtorno metabólico de carboidratos, proteínas e gorduras, consecutivo de falha da secreção e/ou da ação da insulina. Pode ser classificada 
em quatro classes: tipo 1, tipo 2, gestacional e outros outros tipos específicos mais raros (DE LIMA et al, 2017).

O DM tipo 1 é menos comum na população em geral, sendo mais recorrentes em crianças e adolescentes sem excesso de peso, mas podendo ocorrer em adultos. Caracteriza-se pela hiperglicemia excessiva progredimento ligeiramente para cetoacidose, principalmente quando há alguma infecção ou outro tipo de estresse. "Tipo 1" significa o processo de degradação da célula beta levando-a ao modo de deficiência total de insulina, sendo necessária a administração desta para prevenir a cetoacidose. Assim, essa degradação celular pode ser por meio autoimune (tipo 1A) sendo identificado por anticorpos circulantes ou de forma menos comum onde o motivo é desconhecido ( tipo 1B) (BRASIL, 2013).

Já o DM tipo 2 se inicia capcioso e com sintomas mais tranquilos. Apresenta-se em adultos com excesso de peso corriqueiro e com antecedentes familiares. O termo "tipo 2" é usado quando há uma resistência na atividade da insulina conjunto a uma falha na sua secreção. Esse tipo pode evoluir por anos sem se quer necessitar de reposição de insulina para seu controle. Porém, seu uso é para obter um equilíbrio do quadro glicêmico (BRASIL, 2013).

O diabetes gestacional é menos severo que o tipo 1 e 2, é uma hiperglicemia apresentada primeiramente na gravidez sendo solucionada no pós-parto, porém pode voltar depois de anos. É conhecida como diabetes na gravidez, em qualquer semana de gestação e de seu controle ou não depois do parto (MIRANDA et al, 2017).

O aumento dessa doença está ligado à acelerada urbanização, sedentarismo, transição epidemiológica, excesso de peso, alteração nutricional, crescimento e aumento da sobrevida das pessoas diabéticas. Podendo trazer alta morbimortalidade, as complicações agudas e crônicas provocam custos altos para os sistemas de saúde. Mundialmente, esses gastos são em torno de $11,6 \%$ do total das despesas com a saúde, não sendo diferente no Brasil (BRASIL, 2013). 
O desequilíbrio do diabetes mellitus pode acarretar disfunção e morte muitos órgãos, principalmente rins, nervos, coração, vasos sanguíneos e olhos. Está, também, relacionado ao crescimento da mortalidade e o grande risco de desenvolver problemas micro e macrovasculares, tal como de neuropatias. $O$ risco de chegar apresentar essas complicações é maior em pessoas diabéticas: 30 vezes para cegueira, 40 vezes para amputações de membros inferiores, 2 a 5 vezes para IAM e 2 a 3 vezes para AVC (BRASIL, 2013).

Dentre as complicações, as úlceras de pés (pé diabético) e a amputação de membros são as mais relevantes e de grande impacto socioeconômico. São responsáveis por $40 \%$ a $70 \%$ das amputações não acidentais de extremidades inferiores, onde 85\% são antecedidas de ulcerações (ARAÚJO, 2019).

Essas ulcerações podem ter procedência isquêmica, neuropática ou mista. Evidencia-se o pé isquêmico por história de falha intermitente, ou seja, dor em repouso podendo ter piora com atividade física ou elevação do membro superior. Na inspeção pode apresentar rubor postural do pé e palidez ao levantar o membro inferior. O pé se evidencia frio e com ausências de pulsos (BRASIL, 2013).

Em relação ao pé neuropático, apresenta-se por sensibilidade dos membros inferiores. O paciente pode relatar formigamentos, queimação que melhora com alguma atividade física ou diminuição da sensibilidade, perder sapatos ou machucado assintomático. Esse pé terá elevação da temperatura por maior fluxo sanguíneo local, mascarando o diagnóstico, levando a acreditar uma possível infecção de partes moles. No entanto, a diminuição da sensibilidade é o principal achado (BRASIL, 2013).

O ideal é que todo indivíduo com DM faça o exame dos pés anualmente, detectando fatores de risco para ulceração e amputação. A consulta de acompanhamento de pessoas diabéticas deve possuir a anamnese e o exame físico para uma avaliação da sensibilidade e da integridade dos pés podendo diminuir possíveis danos (BRASIL, 2013).

A enfermagem é de extrema importância em casos como esses, pois ela estimulará a importância do autocuidado desses pacientes. Traz com ela a 
Teoria do Autocuidado ao acreditar na capacidade que a pessoa tem em realizar o cuidar de si, comprovando a estratégia de competência do ser humano a concretização da corresponsabilização com o cuidado com ele mesmo, a conservação, restauração e promoção de sua saúde (DA SILVA, 2016).

\section{Vulnerabilidade, Características do Público Alvo e Ações de Educação na} Saúde.

Para que haja autonomia é muito importante verificar a vulnerabilidade da população. O conceito de vulnerabilidade na Saúde Coletiva é alicerçado nas ações educativas, que utilizam intervenções construtivistas que envolvem a consideração do saber popular e a participação daqueles que vivem os problemas, mas não como técnicos ou cientistas. Amorim Neto e Rosito referem que, "não é possível autonomia sem levar em consideração a vulnerabilidade dos sujeitos" (2007, P. 623). As condições de vida são determinantes da situação social à qual está submetida a população. As condições de vida e as experiências que elas trazem, configuram os contextos de vulnerabilidade, que se atrelam a fragilidade da população e a capacidade de enfrentamento das adversidades. (SEVALHO, 2018).

Tabela 1 - características sociodemográficas dos pacientes

\begin{tabular}{|c|c|}
\hline \multicolumn{2}{|c|}{ PERFIL DOS PACIENTES } \\
\hline \multicolumn{2}{|l|}{ SEXO } \\
\hline Feminino & $55 \%$ \\
\hline Masculino & $45 \%$ \\
\hline \multicolumn{2}{|l|}{ IDADE } \\
\hline Abaixo de 20 anos & $5 \%$ \\
\hline Entre 20 e 30 anos & $5 \%$ \\
\hline Entre 31 e 40 anos & $20 \%$ \\
\hline Entre 41 a 50 anos & $30 \%$ \\
\hline Entre 51 e 60 anos & $35 \%$ \\
\hline Acima de 60 anos & $5 \%$ \\
\hline \multicolumn{2}{|l|}{ ESCOLARIDADE } \\
\hline $\begin{array}{l}\text { Ensino fundamental - } \\
\text { anos iniciais }\end{array}$ & $60 \%$ \\
\hline $\begin{array}{l}\text { Ensino fundamental- } \\
\text { completo }\end{array}$ & $25 \%$ \\
\hline Ensino Médio & $10 \%$ \\
\hline Ensino Superior & $5 \%$ \\
\hline RENDA MENSAL & \\
\hline
\end{tabular}




\begin{tabular}{ll}
\hline Um salário & $85 \%$ \\
\hline Dois salários & $10 \%$ \\
\hline Três salários & $5 \%$ \\
\hline ESTADO CIVIL & \\
\hline Casado & $75 \%$ \\
Solteiro & $25 \%$ \\
\hline
\end{tabular}

Fonte: Própria autora.

Observa-se o risco maior para desenvolver a DM2 são em pessoas do sexo masculino. Quanto à idade, ocorre por volta da faixa etária dos 41 a 60 anos. No estudo, grande parte dos pacientes estudou até o ensino fundamental não chegando a completá-lo. Boa parte da amostra apresenta renda mensal de apenas um salário mínimo e são casados.

Segundo estudo, mulheres são mais propensas a apresentarem ulcerações nos pés proveniente do DM2. Além disso, mostrou-se de risco pessoas com idade acima dos 60 anos. Em relação ao estado civil, escolaridade e renda mensal, apresentaram concordância com os números apresentados nesta pesquisa (SILVA, 2017).

\section{Gráfico 01 - É diabético há quanto tempo?}

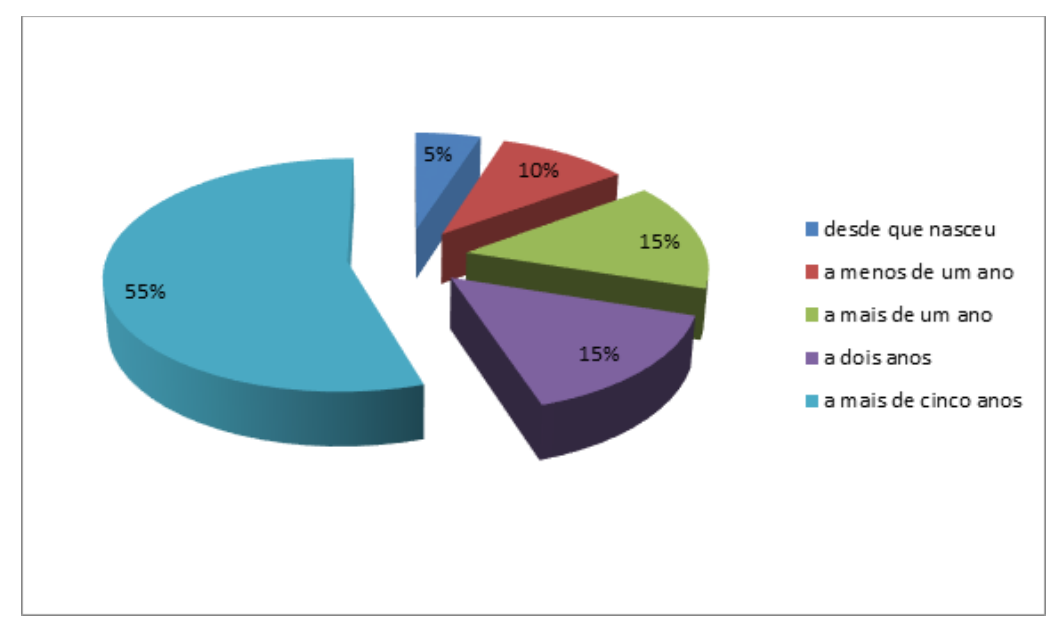

Fonte: Própria autora.

Um autor evidenciou que maior parte dos pacientes têm conhecimento de seu diagnóstico acima de 10 anos, assim, pode-se relacionar que maior parte da população sabe de seu diagnóstico brevemente, o que colabora para um maior entendimento e aquisição do autocuidado (COUSELO-FERNANDEZ, 2018). 


\section{Gráfico 02 - Você tem alguma ferida em seus pés?}

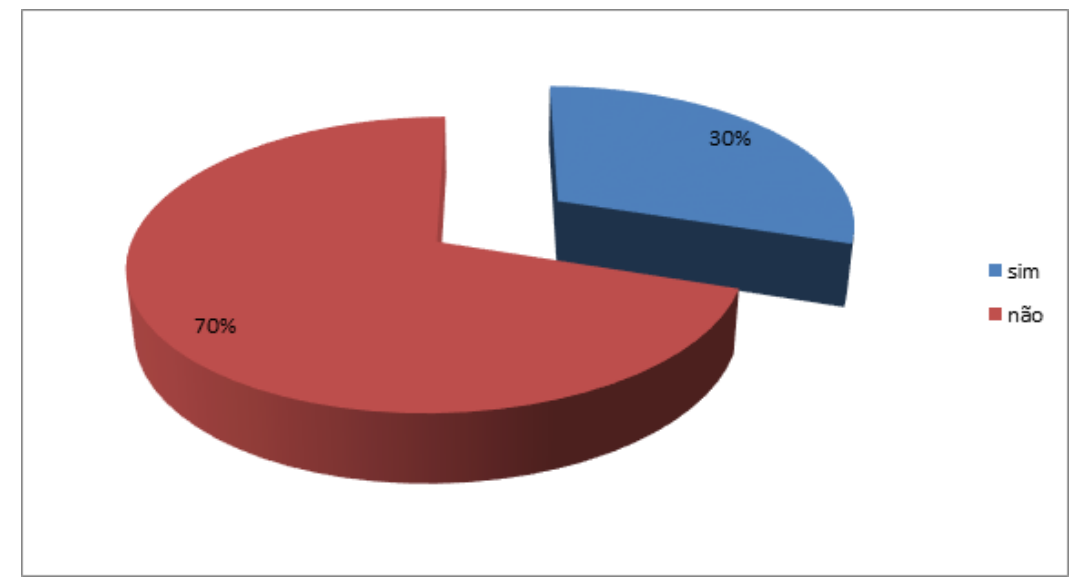

Fonte: Própria autora.

A partir da coleta de dados, é feita a análise a adesão ao tratamento, aos dados relacionados ao uso das medicações e da verificação do nível de glicemia a grande maioria, 90\%, declarou que aferia seu índice glicêmico a mesma porcentagem refere que toma regularmente suas medicações. Porém os índices de adesão caem em relação a para os meios não biologicista e não farmacológicos, importantes ações de controle da glicemia, sendo a minoria, $40 \%$, que aderem às ao controle dietético e a realização de atividades físicas, o que é um dado muito importante, principalmente observando a incidência, de $30 \%$ dos pacientes com feridas nos pés. O que traz a possibilidade, da utilização de um modelo de educação em saúde tradicional.

Couselo-Fernandez traz uma amostra em que $61,9 \%$ dos homens e $67,8 \%$ das mulheres tinham uma alimentação equilibrada, praticavam exercícios físicos e faziam o uso de antidiabéticos para controle da doença e menor risco de desenvolver lesões nos pés. Porém, o único dado da presente pesquisa que condiz com o artigo base foi a porcentagem de pacientes que aderem ao uso de antidiabéticos. Enfatiza-se que a prática de exercícios físicos e assentir a uma dieta balanceada são de extrema importância para a prevenção do pé diabético, sendo estes significativos aspectos do cuidado em si, principalmente sendo demonstrado que $30 \%$ da amostra têm feridas nos pés. (COUSELOFERNANDEZ, 2018). 


\section{Gráfico 03 - Vai sempre ao Posto de Saúde do Bairro?}

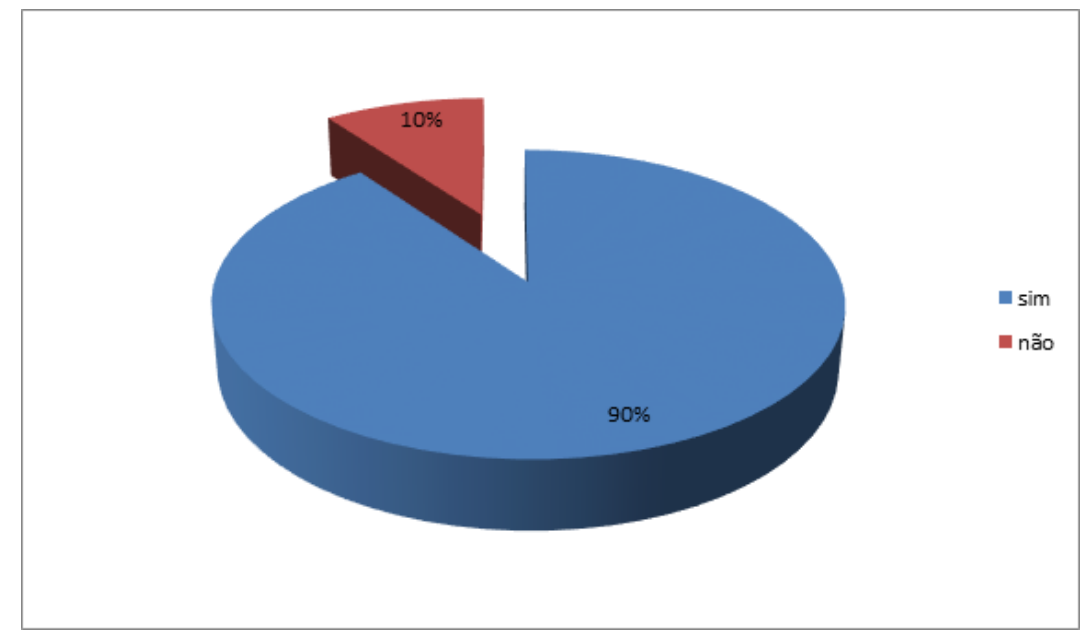

Fonte: Própria autora.

Gráfico 04 - Participou de alguma palestra sobre Diabetes (oferecida pela Estratégia de Saúde da Família)?

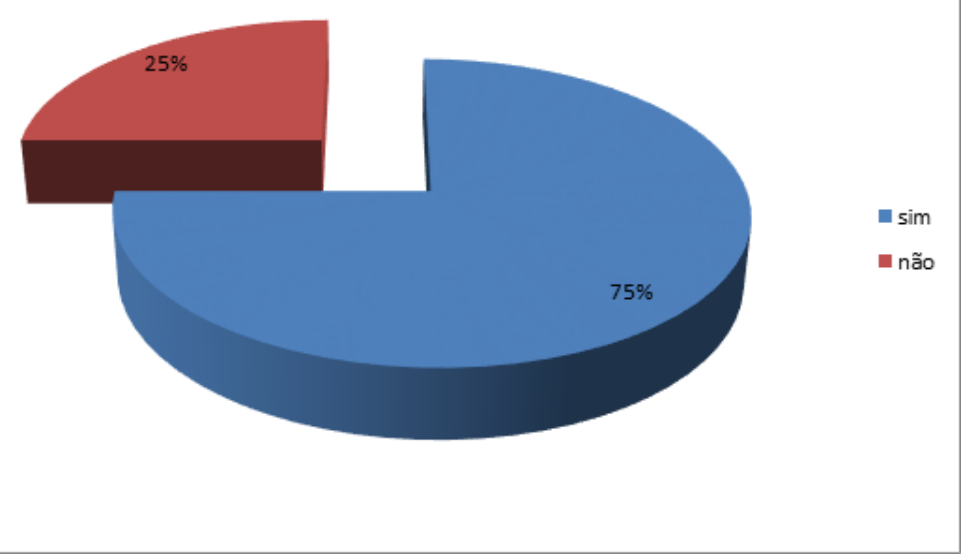

Fonte: Própria autora.

É possível observar que $90 \%$ da população de estudo, grande maioria, costuma frequentar a UBS, o que traz mais condições para atingir, através das ações de educação em saúde, a maior parte população residente na comunidade e usuária da unidade. Por frequentar constantemente a unidade é torna-se viável o planejamento de ações de educação em saúde mais elaboradas, que utilizem metodologias comprovadas cientificamente, relacionadas a educação popular em saúde. 
É necessário perceber que $25 \%$ declaram não ter participado de palestras, sobre diabetes, realizadas pela estratégia de saúde da família. Confrontado esse dado, com a porcentagem de pessoas que frequentam as UBS, será percebido que $15 \%$ da população frequenta a UBS, mas não participou das palestras, o que é necessário ser investigado.

\section{Gráfico 05 - Já ouviu falar de pés diabéticos?}

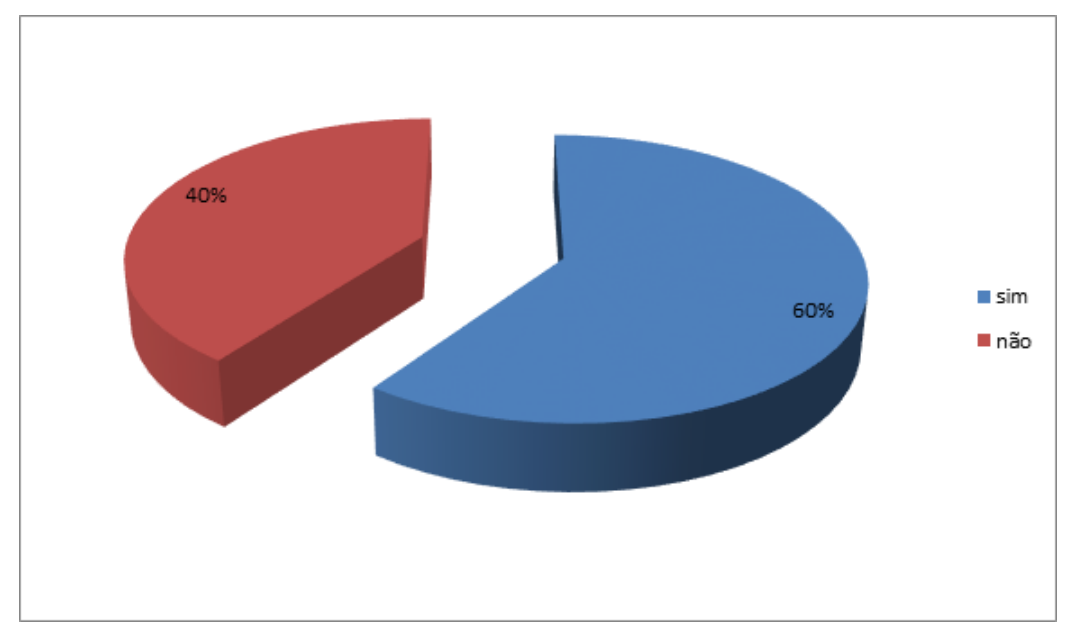

Fonte: Própria autora.

Acerca do conhecimento sobre Pé diabético, 40\% da amostra declarou que não havia ouvido sobre pé diabético, e a mesma porcentagem foi encontrada ao realizar a pergunta sobre o não conhecimento sobre o perigo do agravo. Quando é feita a correlação com o dado das pessoas que participaram de palestras sobre diabetes, observa-se que houve $75 \%$ de pessoas que participaram e 60\% declararam que já ouviram falar sobre Pé Diabético e o mesmo ocorreu para aqueles que sabiam os riscos da doença. $O$ que deve ser analisado com a intenção de tentar dar mais ênfase ao problema. 


\section{Gráfico 06 - Que ações você executa em prol da prevenção de pés diabéticos?}

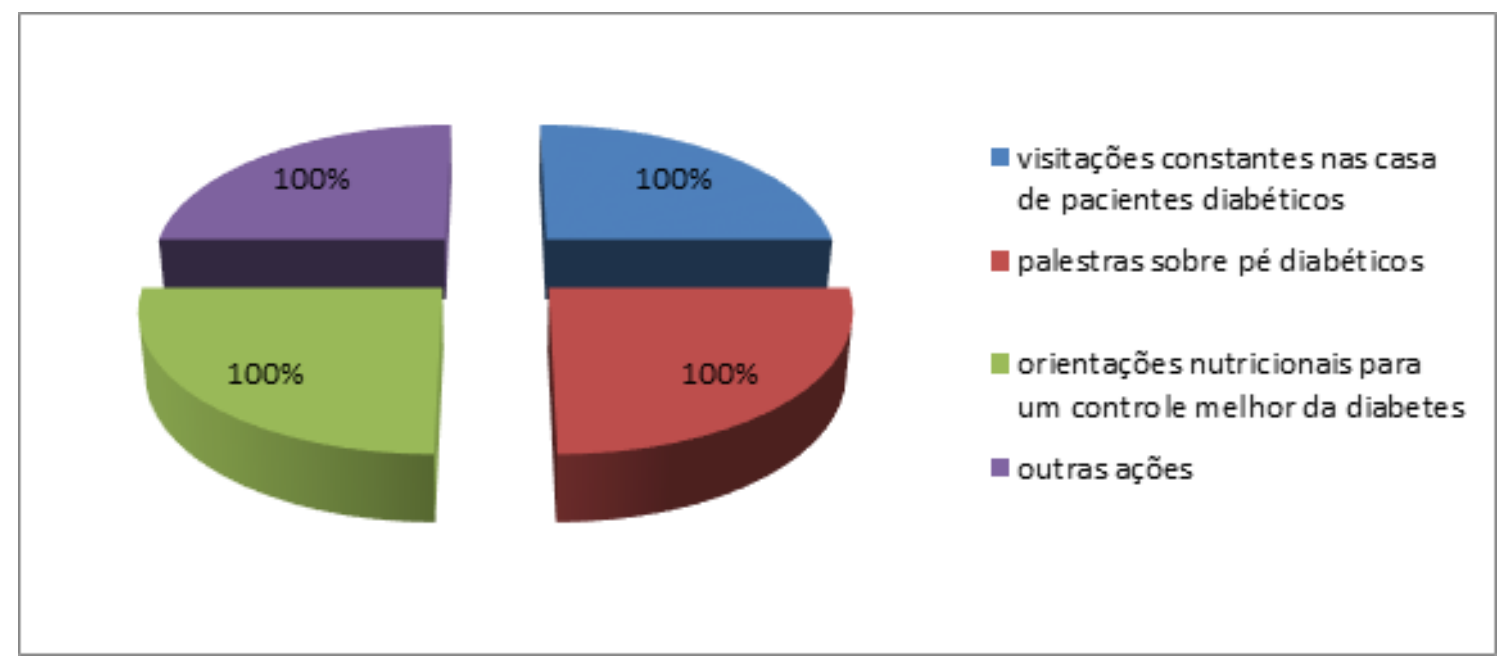

Fonte: Própria autora.

Foi perguntado aos enfermeiros do programa Estratégia em Saúde da Família se utilizam tudo que aprenderam sobre diabetes para a melhoria de vida dos pacientes diabéticos acompanhados por eles e se eles se preocupavam em orientar os pacientes das Unidades em relação ao pé diabético, Todos responderam que sim. Isso demonstra o empenho dos profissionais na Educação em Saúde da população. Quando perguntados das ações de prevenção de pé diabético que eles realizam, foi referido que todos realizam: visita domiciliar, palestras sobre Pé Diabético, orientações nutricionais de com o intuito de promover o controle glicêmico e outras ações diversas, realizadas de acordo com as necessidades apresentadas pelos pacientes.

É indispensável dos profissionais da saúde, principalmente da atenção básica, o desenvolvimento campanhas educativas, de maneira perene, e grupos de educação em saúde e de ajuda mútua, visando promover estilos de vida saudáveis, realizando a melhoria do controle glicêmico e metabólico e adesão medicamentosa, que previne complicações agudas e crônicas como o pé diabético, o que tem sido explicitado em várias literaturas. Para além, as ações de educação em saúde são fundamentais para informar as pessoas adoecidas, motivar e capacitar esses pacientes para lidar com sua condição e cumprirem seu plano de tratamento. Logo, as ações de educação em saúde, especialmente em grupo, promovem oportunidades de socialização de conhecimentos e 
compartilhamento de experiências sobre a vida com o DM, o que confere maior autonomia no autocuidado ao indivíduo adoecido e aos seus familiares (MELO, 2016).

\section{Pesquisa qualitativa: Educação Popular.}

\section{Área de estudo}

O estudo foi realizado em duas Unidades Básicas de Saúde, estas são compreendidas como locais normalmente localizados próximos às residências que possibilitará a população o acesso à atenção básica, esta é a porta de entrada, deve ser o contato preferencial dos usuários, o centro de comunicação de toda rede de atenção à saúde (BRASIL, 2012).

Localizado no município do Recife, encontra-se na região litorânea, é a capital do Estado de Pernambuco, no nordeste brasileiro. Contém área territorial de $218 \mathrm{~km}^{2}$ onde habitam 1,6 milhões de pessoas e tem o melhor Índice de Desenvolvimento Humano da região.

\section{Tipo de Pesquisa}

Estudo do tipo qualitativo que é caracterizado pela importância das questões da realidade que não podem ser quantificadas, concentrando-se na clareza e esclarecimento das relações sociais (GERHARDT, 2009).

$O$ estudo foi realizado com Enfermeiros e pacientes portadores de pé diabético de duas Unidades Básicas de Saúde do Recife. Consistiu em uma entrevista para os enfermeiros que se perguntava sobre idade, sexo, se havia alguma especialização quanto enfermeiro, o tempo de serviço, o tempo de atuação na Estratégia Saúde da Família, se gosta de atender o público popular, se possui muitos pacientes diabéticos, quanto à preocupação a orientar esses pacientes em relação ao pé diabético, quais tipos de ações executaram para orientações de prevenção do pé diabético, se muitos dos seus pacientes têm o pé diabético, se algum dos pacientes sofreu amputação por conta do pé diabético e em relação a usar tudo o que aprendeu para melhoria da vida dos pacientes diabéticos acompanhados por ele. 
A entrevista com os pacientes portadores de pé diabético foram com base nas seguintes investigações: sexo, idade, escolaridade, renda mensal, estado civil, tempo de diagnóstico de DM, regularidade na ingestão da medicação controlada, controle da glicose, frequência de ida a unidade de saúde, participação em palestra sobre diabetes realizada pela equipe da ESF, conhecimento sobre o pé diabético, presença de lesões nos pés, prática de exercícios físicos, alimentação equilibrada e o perigo de um pé diabético.

\section{CONCLUSÃO}

A educação em saúde tem sido realizada de forma hierárquica e vertical, indo contra o conceito de educação popular de Paulo Freire, patrono da educação no Brasil, o que é uma grande contradição. É imprescindível a observação e análise, contínua do déficit de congruência entre o ensino e as necessidades sociais de saúde e sua correlação a capacidade de resposta no sistema de saúde brasileiro a intervir nas situações de saúde da Diabetes e do Pé Diabético.

A Educação Popular em Saúde é principal alternativa para trazer a autonomia aos usuários em vulnerabilidade do SUS. Seu enfoque na obtenção de dignidade humana, e além, do protagonismo do povo, realizado principalmente participação popular nas decisões sociais e principalmente de saúde. O povo sendo sujeito de sua própria história, empodera e consequentemente, promove saúde.

No caso da Diabetes, o diálogo horizontal com o povo dá autonomia a ele, para que seja realizado o seu autocuidado. Autocuidado que é um dos aspectos observados nos diagnósticos de enfermagem, e tem grande importância para a prevenção de agravos, como o Pé Diabético, pois o controle da própria alimentação, a realização de exercícios, a adesão medicamentosa e ao acompanhamento de saúde necessita de sua participação ativa.

Os profissionais de saúde que são detentores de conhecimento científico acerca das doenças têm a obrigação e o trabalho de utilizar linguagem e metodologias populares, que conversem diretamente com o povo. Desta forma, 
fazendo com que os usuários do nosso SUS entendam a importância deles na própria saúde.

\section{REFERÊNCIAS}

AIMONDI, Gustavo Antonio et al. Intersetorialidade e Educação Popular em Saúde: no SUS com as Escolas e nas Escolas com o SUS. Rev. bras. educ. med., Brasília, v. 42, n. 2, p. 73-78, 2018. doi: 10.1590/198152712015v42n2rb20170043

ARAÚJO, Lilianny Sales et al. Pé diabético: perfil sócio epidemiológico de pacientes atendidos em um hospital público do sertão central. Encontro de Extensão, Docência e Iniciação Científica (EEDIC), v. 4, n. 1, 2019.

BRASIL. Ministério da Saúde. Departamento de monitoramento e avaliação da gestão do SUS. Temático Promoção da Saúde IV. Brasília, DF: Organização Pan-Americana da Saúde; 2009. Disponível em: http://bvsms.saude.gov.br/bvs/publicacoes/painel indicadores sus promocao saude.pdf.

BRASIL. Ministério da Saúde. Estratégias para o cuidado da pessoa com doença crônica. Cadernos de Atenção Básica, n. 35, 2014.

BRASIL. Ministério da Saúde. Estratégias para o cuidado da pessoa com doença crônica: diabetes mellitus. Cadernos de Atenção Básica, n. 36, 2013.

BRASIL. Ministério da Saúde. II Caderno de educação popular em saúde. Ministério da Saúde, 2014.

BRASIL. Ministério da Saúde. Política Nacional de Atenção Básica. Ministério da Saúde, 2012.

BRASIL. Ministério da Saúde. Portaria no 2.436, de 21 de setembro de 2017. Aprova a Política Nacional de Atenção Básica, estabelecendo a revisão de diretrizes para a organização da Atenção Básica, no âmbito do Sistema Único de Saúde (SUS). Diário Oficial da União, 2017. 
BRASIL. Ministério da Saúde. Portaria 2.761, de 19 de novembro de 2013. Institui a Política Nacional de Educação Popular em Saúde no âmbito do Sistema Único de Saúde (PNEPS-SUS). Diário Oficial da União, 2013.

BRASIL. Ministério da Saúde. Protocolo Clínico e Diretrizes Terapêuticas Diabetes Mellitus Tipo 1. Comissão Nacional de Incorporação de Tecnologias, 2019.

COUSELO-FERNANDEZ, I.; RUMBO-PRIETO, J.M.. Riesgo de pie diabético y déficit de autocuidados en pacientes con Diabetes Mellitus Tipo 2. Enferm. univ, México, v. 15, n. 1, p. 17-29, marzo 2018.

DANTAS, Mayana Azevedo; SILVA, Maria Rocineide Ferreira da; CASTRO JUNIOR, André Ribeiro de. Aprendizagens com o corpo todo na (trans)formação de educadores (as) populares do Curso Livre de Educação Popular em Saúde (EdPopSUS). Interface (Botucatu), Botucatu, v. 24, e190205, 2020. doi: 10.1590/interface.190205.

DA SILVA, Luzia Wilma Santana et al. Promoção da saúde de pessoas com diabetes mellitus no cuidado educativo preventivo do pé-diabético. Ciencia y enfermería, v. 22, n. 2, p. 103-116, 2016.

DE LIMA, Imaikon Gomes et al. Educar para prevenir: A importância da informação no cuidado do pé diabético. Revista Conexão UEPG, v. 13, n. 1, p. 186-195, 2017.

GERHARDT, Tatiana Engel; SILVEIRA, Denise Tolfo. Métodos de pesquisa. Plageder, 2009.

GONCALVES, Fernanda Carneiro Leão; DAL-FARRA, Rossano André. A educação libertadora de Paulo Freire e o teatro na educação em saúde: experiências em uma escola pública no Brasil. Pro-Posições, Campinas, v. 29, n. 3, p. 401-422, 2018. doi: 10.1590/1980-6248-2015-0159

GRUPO DE TRABALHO INTERNACIONAL SOBRE PÉ DIABÉTICO. Consenso internacional sobre pé diabético. 2001. 
MELO, Lucas Pereira de. É como uma família: significados atribuídos a grupos de educação em saúde sobre diabetes por profissionais da saúde. Ciência \& Saúde Coletiva, v. 21, p. 2497-2506, 2016.

LIMA, Geisa Carla de Brito Bezerra et al . Educação em saúde e dispositivos metodológicos aplicados na assistência ao Diabetes Mellitus. Saúde debate, Rio de Janeiro, v. 43, n. 120, p. 150-158, 2019. doi: 10.1590/0103-1104201912011.

MACIAZEKI-GOMES, Rita de Cássia et al . O trabalho do agente comunitário de saúde na perspectiva da educação popular em saúde: possibilidades e desafios. Ciênc. saúde coletiva, Rio de Janeiro, v. 21, n. 5, p. 1637-1646, maio 2016. doi: 10.1590/1413-81232015215.17112015.

MIRANDA, Alexandra et al. Diabetes gestacional: avaliação dos desfechos maternos, fetais e neonatais. Rev Port Endocrinol Diabetes Metab, v.12, n. 1, p. 35-44, 2017.

NETO, Roque do Carmo Amorim; ROSITO, Margaréte May Berkenbrock. Freire, Dussel e Kohlberg: da vulnerabilidade à autonomia. Revista Contrapontos, v. 7, n. 3, p. 615-627, 2009.

PARO, César Augusto; VENTURA, Miriam; SILVA, Neide Emy Kurokawa. Paulo Freire e o inédito viável: esperança, utopia e transformação na saúde. Trabalho, Educação e Saúde, v. 18, n. 1, 2020. doi: 10.1590/1981-7746-sol00227.

SEVALHO, Gil. O conceito de vulnerabilidade e a educação em saúde fundamentada em Paulo Freire. Interface (Botucatu), Botucatu, v. 22, n. 64, p. $177-188,2018$. doi: 10.1590/1807-57622016.0822

SILVA, Juliana Marisa Teruel Silveira da et al . Fatores associados à ulceração nos pés de pessoas com diabetes mellitus residentes em área rural. Rev. Gaúcha Enferm., Porto Alegre , v. 38, n. 3, e68767, 2017.

SOCIEDADE BRASILEIRA DE DIABETES. Diretrizes da Sociedade Brasileira de diabetes. 2019-2020. Rio de Janeiro, 2019. Disponível em: $<$ https://www.diabetes.org.br/profissionais/images/DIRETRIZES-COMPLETA2019-2020.pdf> 